\author{
I.M. Gasiuk, D.M. Chervinko, M.I. Gasiuk, L.Ya. Lozinska
}

\title{
Phenomenology of the Temperature-Frequency Dispersion of Electrical Properties of Aluminium-Substituted Lithium-Iron Spinel
}

\author{
Vasyl Stefanyk Precarpathian National University, Ivano-Frankivsk, Ukraine, e-mail: gasyukim@gmail.com, \\ dmytro.chervinko@gmail.com
}

\begin{abstract}
The conductivity of the Li-containing Al-oxoferrite samples has been studied. Using Jonsher's phenomenological approach, existence of 2 types of conductivity (electronic and ionic) in the above mentioned samples has been confirmed. Using Cole-Cole method, the character of electrical conductivity dispersion of the samples has been shown. The activation energy for the series of samples have been calculated. It has been found that the ionic contribution to the total conductivity of the system is much lower that the corresponding electronic contribution.
\end{abstract}

Keywords: Jonsher's phenomenological approach, Cole-Cole method, electrical conductivity dispersion.

Стаття поступила до редакиії 20.11.2019; прийнята до друку 15.12.2019.

\section{Introduction}

Lithium-containing complex spinel oxides are widely used nowadays in the role of magnetic materials for microwave devices and intercalated matrices as cathodes for lithium current sources [1]. This fact gives rise to a large number of theoretical and practical problems related to the study of structural, morphological and electrophysical properties of these materials depending on their synthesis. It is known that spinel materials belong to semiconductors and cationic substitution is often used to optimize their electrical conductivity. Cationic substitution not only changes the value of the specific conductivity but also changes the mechanism of conductivity and the concentration of the current carriers. The nature of current carriers is also important, as far as the mechanisms of charge-mass transfer in such, often highly disordered, systems.

In $[2,3]$ were shown the possibility of forming Alsubstituted lithium-iron spinel for cathodes of a lithium current source in one technological process. However, taking into account the heterophase of such a system, its individual morphological components are suitable both for the intercalation of $\mathrm{Li}^{+}$into the spinel structure, as far as for the transport of conduction electrons to the sites of electrochemical reactions during the charge-discharge process of a lithium current source. At the same time, it remains unknown what is the contribution of different charge carriers to the total current generation, as far as the nature of the formation of intercalation-current flows in such a matrix.

In this paper the contribution of electronic and ionic $\left(\mathrm{Li}^{+}\right)$components of conductivity is determined based on the analysis of the concentration and temperaturefrequency dependences of the electrical impedance spectra of complex $\mathrm{Li}-\mathrm{Al}-\mathrm{Fe}-\mathrm{O}$ ceramic systems. The mechanisms of current formation based on phenomenological models are also explained.

\section{Experimental technique}

Ceramics of general composition $\mathrm{Li}_{0.5} \mathrm{Fe}_{2.5-\mathrm{y}} \mathrm{Al}_{\mathrm{y}} \mathrm{O}_{4}$, де $\mathrm{y}=0.6 ; 0.8 ; 1.0$ was synthesized from the source oxides $\mathrm{Li}_{2} \mathrm{O}, \mathrm{Fe}_{2} \mathrm{O}_{3}, \mathrm{Al}_{2} \mathrm{O}_{3}$ using standard ceramic technology [4].

The content ratio of the components was chosen in order to obtain complex disordered compounds at the boundary of metastable states [5, 6], Figure 1.

Samples have been sintering in air $(T=1273 \mathrm{~K})$ for $5 \mathrm{~h}$. To ensure the various structural forms of substituted lithium-iron spinel, the samples from Series 1 were 


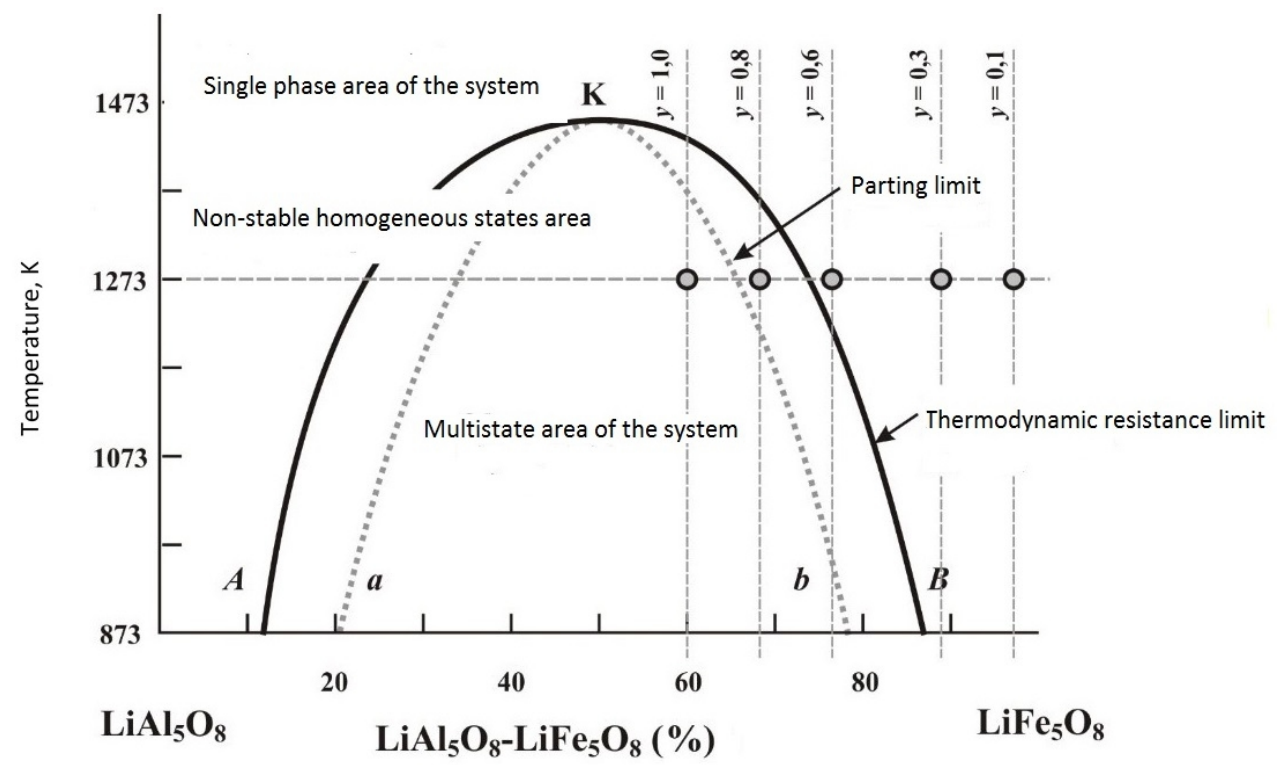

Fig. 1. Temperature phase diagram of the spinel system $(1-y) \mathrm{LiFe}_{5} \mathrm{O}_{8}+(y) \mathrm{LiAl}_{5} \mathrm{O}_{8}$ [5].

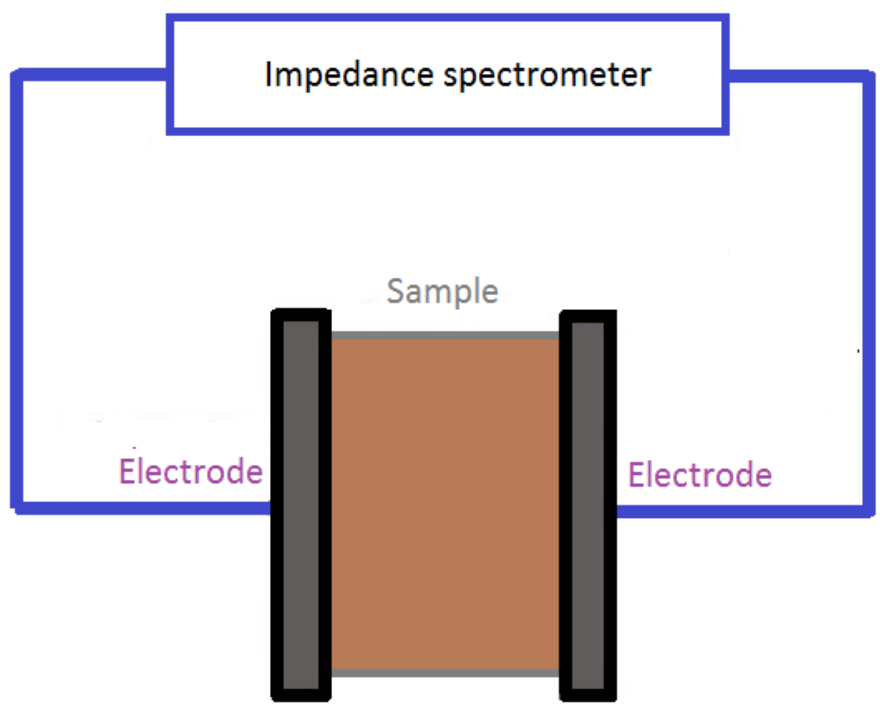

Fig. 2. Impedance measurement scheme.

Table 1

cooled together with the furnace and the average cooling rate was $V_{m} \approx 0.03 \mathrm{~K} / \mathrm{c}$. Samples from Series 2 were quenched in water from the synthesis temperature $V_{c} \approx 90 \mathrm{~K} / \mathrm{s}$.

The phase composition of the obtained samples and the basic structural characteristics for two series of samples obtained by the results of X-ray analysis, are given in tables 1, 2. [5, 6].

The temperature and concentration dispersion dependences of the electrical parameters of the system were calculated using Nyquist diagrams (parametric dependencies $Z^{\prime \prime}\left(Z^{\prime}\right)$ ) obtained on an Autolab PGSTAT 12/FRA-2 impedance spectrometer. The capacitor scheme for measurements is presented on Figure 2.
Phase composition of the synthesized samples from Series 1,\%

\begin{tabular}{|c|c|c|c|}
\hline \multirow{2}{*}{ Phase, \% } & \multicolumn{3}{|c|}{ Substitution degree, $y$} \\
\cline { 2 - 4 } & 0.6 & 0.8 & 1.0 \\
\hline $\mathrm{Li}_{0.5} \mathrm{Al}_{y} \mathrm{Fe}_{2.5-y} \mathrm{O}_{4}$ & 93.17 & 94.54 & 92.08 \\
\hline$\alpha-\mathrm{Fe}_{2} \mathrm{O}_{3}$ & 6.83 & 5.06 & 0 \\
\hline$\sigma-\mathrm{Al}_{2.667} \mathrm{O}_{4}$ & 0 & 0.4 & 7.92 \\
\hline
\end{tabular}

Measurement of electrical impedance was done in the frequency range $0.01 \mathrm{~Hz}-100 \mathrm{kHz}$, the temperature range was $298-648 \mathrm{~K}$.

The frequency dispersion of electrical conductivity is determined from the Nyquist diagrams by formula (2). formula:
The electrical conductivity is determined by the 
Phase composition of the synthesized samples from Series 2, \%

\begin{tabular}{|c|c|c|c|c|c|}
\hline \multirow{2}{*}{ Phase, \% } & \multicolumn{5}{|c|}{ Substitution degree, $y$} \\
\cline { 2 - 6 } & 0.1 & 0.3 & 0.6 & 0.8 & 1.0 \\
\hline $\mathrm{Li}_{0.5} \mathrm{Al}_{y} \mathrm{Fe}_{2.5-y} \mathrm{O}_{4}$ & 93.92 & 73.86 & 90.46 & 78.8 & 92.91 \\
\hline$\alpha-\mathrm{Fe}_{2} \mathrm{O}_{3}$ & 6.08 & 26.14 & 9.54 & 18.54 & 0 \\
\hline$\sigma-\mathrm{Al}_{2.667} \mathrm{O}_{4}$ & 0 & 0 & 0 & 2.66 & 7.09 \\
\hline
\end{tabular}

$$
\sigma=\frac{1}{Z *}=\frac{S}{\rho * \cdot l},
$$

where $Z^{*}, \rho *$ - complex impedance and electrical resistivity, respectively; $S, l-$ the square and thickness of the sample, respectively.

Using diagram $\sigma^{\prime}-\left(\sigma^{\prime \prime}-\varepsilon_{0} \varepsilon_{\infty} \omega\right)\left(\varepsilon_{\infty}-\right.$ values of dielectric constant at high frequencies) in the lowfrequency region, the value of the specific conductivity of ceramics at direct current $\sigma_{\mathrm{dc}}$ at different temperatures was determined. Value of $\varepsilon_{\infty}$ is determined using ColeCole diagram $\varepsilon^{\prime \prime}-\varepsilon^{\prime}$ by approximation of the experimental curve to the intersection with the abscissa [7].

The frequency dependence of the true component of complex conductivity was determined from the formula:

$$
\sigma^{\prime}(\omega)=\frac{\rho^{\prime}(\omega)}{\left(\rho^{\prime \prime}(\omega)\right)^{2}+\left(\rho^{\prime}(\omega)\right)^{2}},
$$

where $\omega=2 \pi \mathrm{f}$.

To determine the energy parameters of charge transfer and its nature, temperature dependences $\sigma_{0}$ were constructed in the form of Arrhenius curves $\ln \sigma_{0}=f\left(\frac{1}{T}\right)$. The activation energy of the conductivity was determined from the approximation curves by the formula:

$$
\Delta E=\frac{k \cdot \ln \frac{\sigma_{01}}{\sigma_{02}}}{T_{2}-T_{1}}
$$

\section{Theoretical approaches to describing the conductivity of complex oxide systems}

Examples of the system deviation from the properties predicted by the Debye model were shown in [8], where the criterion for matching this model was a linear dependence of $\varepsilon^{\prime}$ and $\varepsilon^{\prime \prime}$ (in this case, this ratio is observed only for the low-frequency region of the spectrum). In [9] it is shown that conductivity increases with frequency due to the fact that charged particles do not have time to move from one position to another and start contributing to the dielectric response of the system. This causes an increase in the conduction of the system with increasing of frequency.

This mechanism can be explained by ion drift and weak ion diffusion. Also, in these works one can observe a step change in parameter $S$ with increasing temperature in all frequency ranges.
The criterion for the application of the Jonsher model was shown in [2, 10-13]. In [2], for the BaTiO3 ceramics, the Johnsher model is applied for the scheme of two parallel AC-elements corresponding to two relaxation times. In [11], relation (5) was used to establish the temperature dependence of the exponent $S$. In [11], it was concluded that the weak temperature dependence of the parameter $S$ is a sign to use a symmetric hopping model. According to it, charge transfer is the carrier hopping between close equilibrium positions in the non-periodic potential field and it implies the absence of a clearly defined value of the activation energy. It was shown in [12] that the Jonscher approach can be used to describe the electron polarization phenomenon. The work [13] examines the phenomenological model of the dynamic conductivity of superionic conductors. This model describes the experimental data of the frequency dispersion of the dielectric response in a wide temperature range for the case of ionic conductivity. This approach implies considering one type of charge with stabilized parameters. Particular attention should be paid to the fact that the approximation of the obtained data at low frequencies is similar to the Jonsher's degree-dispersion dependence.

Given the assumption of the presence of electronic and ionic conductivities in Li-containing spinels, the frequency dispersion of electrical conductivity can be described by the following relationship

$$
\sigma(\omega)=\sigma_{\mathrm{e}}(\omega)+\sigma_{\mathrm{i}}(\omega)
$$

where $\sigma_{\mathrm{e}}(\omega)$ - electron, $\sigma_{\mathrm{i}}(\omega)$ - ion conductivity component.

Equation (4) is a superposition of the contributions of Jonsher's conductivities caused by carriers that have different parameters. Attributing to the respective charge carriers their characteristic hopping frequencies (resonant frequencies), stationary conductivities $\sigma_{0 \mathrm{e}}(\omega)$ та $\sigma_{0 \mathrm{i}}(\omega)$, and constants $S_{e}$ i $S_{\mathrm{i}}$, one can obtain (5):

$$
\sigma(\omega)=\sigma_{0 \mathrm{e}}\left[1+\left(\frac{\omega}{\omega_{h e}}\right)^{S_{e}}\right]+\sigma_{0 \mathrm{i}}\left[1+\left(\frac{\omega}{\omega_{h i}}\right)^{S i}\right]
$$

The approximation of the experimental curve by equation (5) makes it possible to separate the contributions of the ionic and electronic components of current generation.

The general view of the impedance spectra of lithium-containing spinels (the presence of a lowfrequency polarization branch) indicates the existence of an ionic component of conductivity in them. However, no attempt has been made to separate the electronic and ionic components of the conductivity in the available 
literature.

For ferrites the electronic type of conductivity is predominant. There are two types of electronic conductivity mechanism: hopping or activation [14]. Speaking about the nature of the dispersion of electron conductivity in ferrites, we can say that it is has normal type which indicates more probably activation mechanism. It can be explained in terms of existence of a local displacement of the electron cloud towards the applied field, as well as, additional polarization and all these factors lead to the anomalous nature of the dielectric constant.

One way to describe the nature of the frequency dispersion of dielectric constant is to use the Jonsher's phenomenological approach.

According to this approach, the frequency variance of the real part of the electrical conductivity for disordered semiconductors is described by equation (6).

$$
\sigma(\omega)=\sigma_{\mathrm{dc}}\left[1+\left(\frac{\omega}{\omega_{h}}\right)^{S}\right],
$$

where $\omega_{h}$ - frequency of current carriers hopping, $\sigma_{\mathrm{dc}}$ system conductivity at direct current, $s-$ an exponent that characterizes the deviation of the system from the properties predicted by the Debye model for low-polar environments. The exponent $s$ can be $0<\mathrm{s}<1$.

\section{Results and discussion}

The temperature dependences for the two series of samples, listed for specific resistivity values in the temperature range 273 - $648 \mathrm{~K}$, are shown in Figure 3, 4.

The general view of the temperature dependence of the spectra indicates the probable semiconductor nature of the conductivity of the system. The low-frequency region is characterized by a poorly resolved polarization curve that can be caused by the effects of charge-mass transfer and the formation of polarization regions in crystallites and at grain boundaries.

Figure $5(\mathrm{a}, \mathrm{b})$ presents the experimental Arrhenius curves for DC conductivities obtained using the intercalation technique from the Cole-Cole theory mentioned above. From the approximations of the experimental dependencies, the direct values of the activation energy of the conductivity are presented in Table 3.

Previously, the curve was approximated by direct dependence. The result of calculating of the conductivity activation energy for both series of samples is shown in table 3 .

The general course of Arrhenius diagrams confirms the semiconductor nature of the conductivity for both sample systems. A strong disordering, heterophase and morphological heterogeneity predetermine the clearly visible anomalous sections of the curves $\ln \sigma_{0}=f\left(\frac{1}{T}\right)$. In the series 2 samples, such fluctuations occur in almost entire temperature range. We assume that the sharp cooling of the samples from the freezing synthesis temperature of the local nonequilibrium states of the spinel phase, shown in [15], results in the formation of a large number of mesostructural inclusions that play the role of small-radius polarons.

Detailed analysis of the course of the curves $\ln \sigma_{0}=$ $f\left(\frac{1}{T}\right)$ shows existence of the anomalous regions in the temperature range from 500 to $556 \mathrm{~K}$ for $\mathrm{y}=0.6$ and from 556 to $625 \mathrm{~K}$ for $\mathrm{y}=0.8$ and the nature of these anomalies is different. For the sample curve $y=0.6$, as the temperature rises in the region of $500-556 \mathrm{~K}$, there is a sharp decrease in the activation energy up to the formation of conductivity. This is similar to the character of the thermal dependence course to the character of the curve's course, after which the nature of the conductivity is restored to the semiconductor type. Instead, for the sample curve $\mathrm{y}=0.8$, as the temperature rises in the region of $500-556 \mathrm{~K}$, a sharp increase in the activation energy of the conductivity is observed, which is characteristic of a semiconductor type of conductivity, after which a similar to a metallic course is observed in a small temperature region.

The deviation from the Arrhenius curve may indicate the heterogeneity of charge carriers by their nature, which is, in principle, hypothetical for the samples under study, since we are dealing with lithium-containing systems that can have ionic conductivity along with a standard semiconductor one.

The cause of anomalous areas on the Arrhenius curves may be:

1. Different type conductivity of the sample. Contribution of both electrons and ions. In the spinel crystal lattice, $\mathrm{Fe}^{2+}$ ions are placed in their octahedral positions that participate in the percolation conductivity of the sample. The conductivity mechanism in this case is hopping. The hopping mechanism is realized by jumping of an electron between the ions of the same element. In order to jump, electron needs to overcome the potential barrier between ions. Also in the lattice nodes there are $\mathrm{Li}^{+}$ions that are usually in a stable

Conductivity activation energy for two series of samples

Table 3

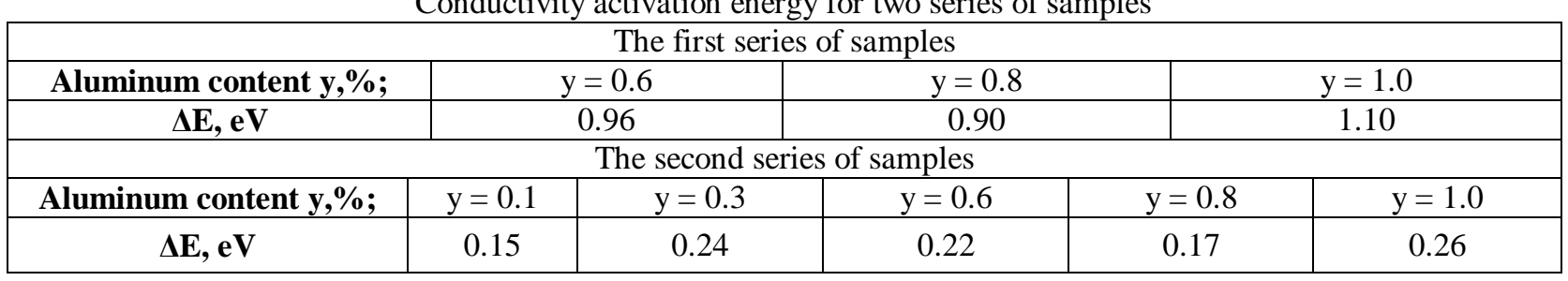


Phenomenology of the Temperature-Frequency Dispersion...
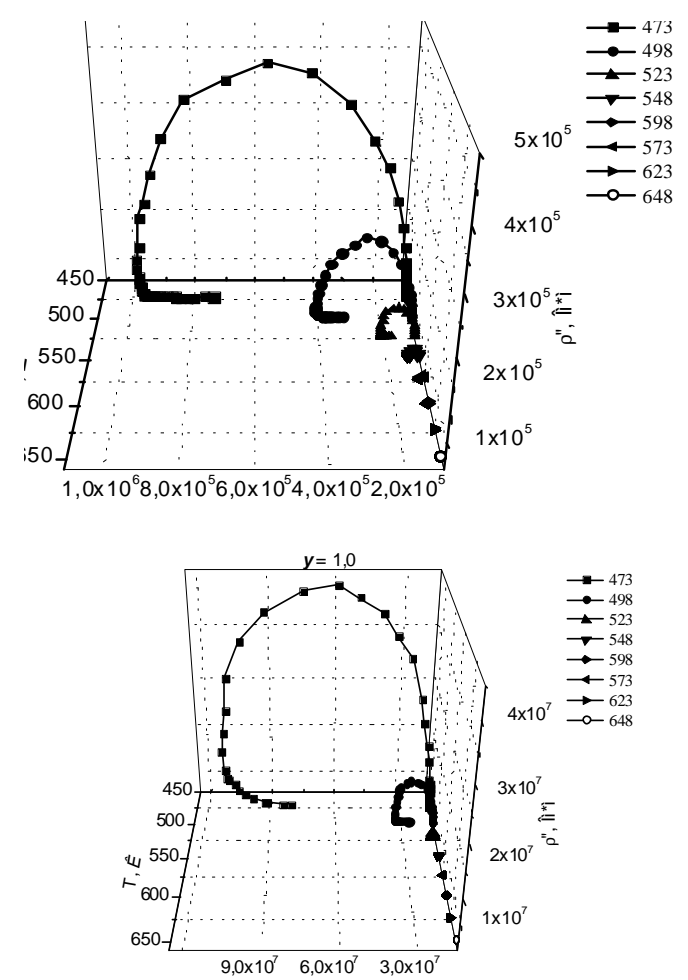

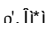
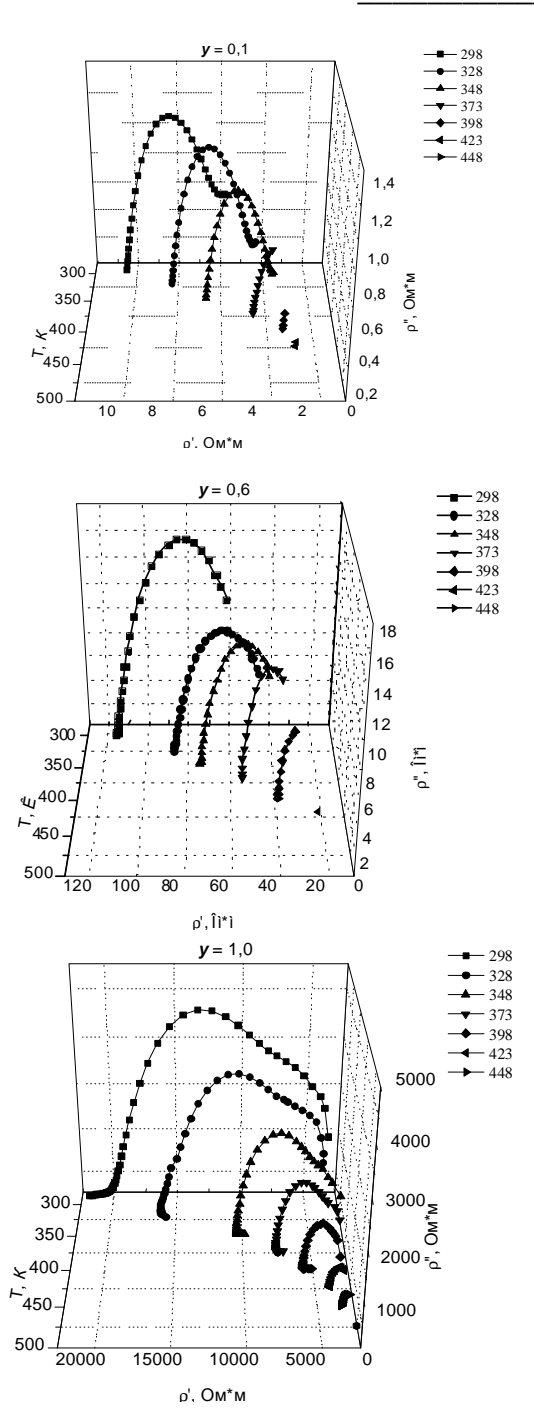

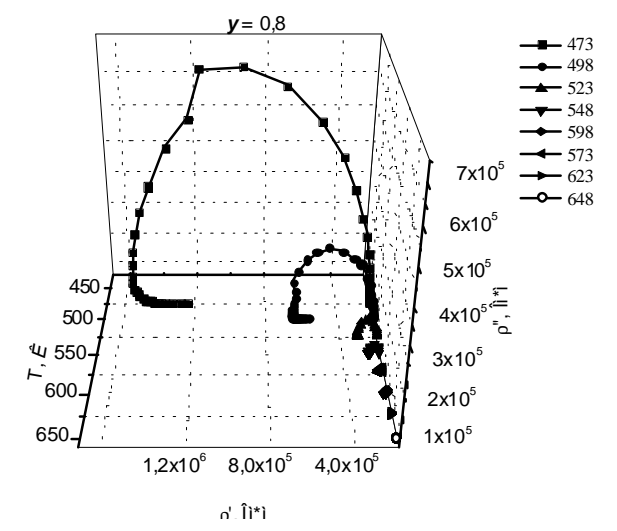

Fig. 3. Nyquist diagrams for the specific values of the complex impedance $\rho^{\prime \prime}\left(\rho^{\prime}\right)$ at different temperatures for the studied samples from Series 1 for $\mathrm{y}=0.6$;

$0.8 ; 1.0$
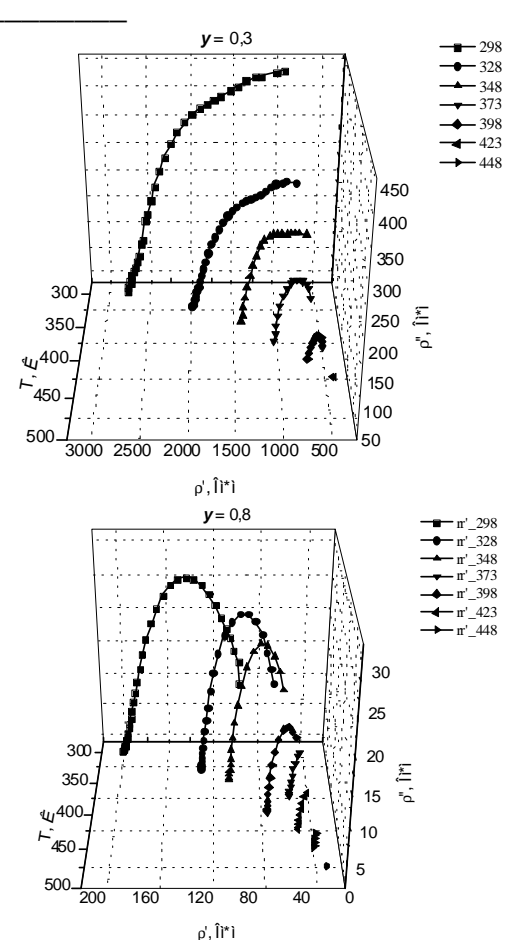

Fig. 4. Nyquist diagrams for the specific values of the complex impedance $\rho^{\prime \prime}\left(\rho^{\prime}\right)$ at different temperatures for the studied samples from Series 2 for $\mathrm{y}=0.1 ; 0.3$; $0.6 ; 0.8 ; 1.0$. 
position and the electric field applied to them does not significantly affect their position. But there are impurities in the structure of the spinel that are weakly bound to the crystal lattice, and after applying an electric field a certain number of weakly bound ions (of their total volume per unit) overcome the potential barrier per unit time, and thus participate in the conductivity process.

2. Ferroelectricity mechanism. For ionic crystals, the phenomenon of spontaneous polarization is possible in some temperature range in the absence of an external electric field [16]. On the other hand, in highly ordered systems with the existence of grains of different phases the grains polarize with the boundaries of the formed polaron of large radius at the boundaries of these grains due to the high relaxation time of $\mathrm{Li}^{+}$ions. When measured in alternating fields at sufficiently high frequencies, the polarized region does not have time to electrically reorient itself, leading to anomalous regions of thermal dependence of the conductivity. These temperature regions correspond to the resonant activation

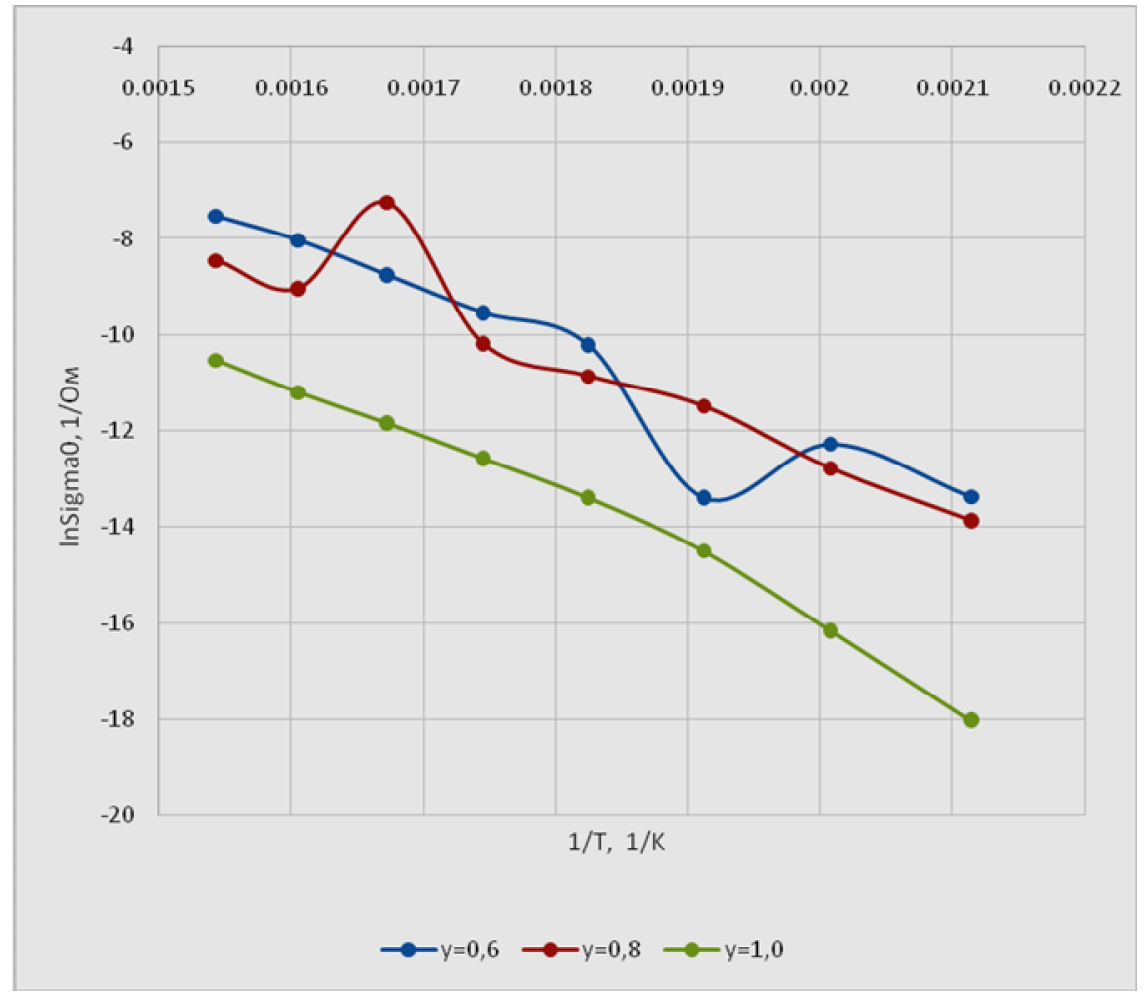

Fig. 5 a. Arrhenius curves (samples from Series 1).

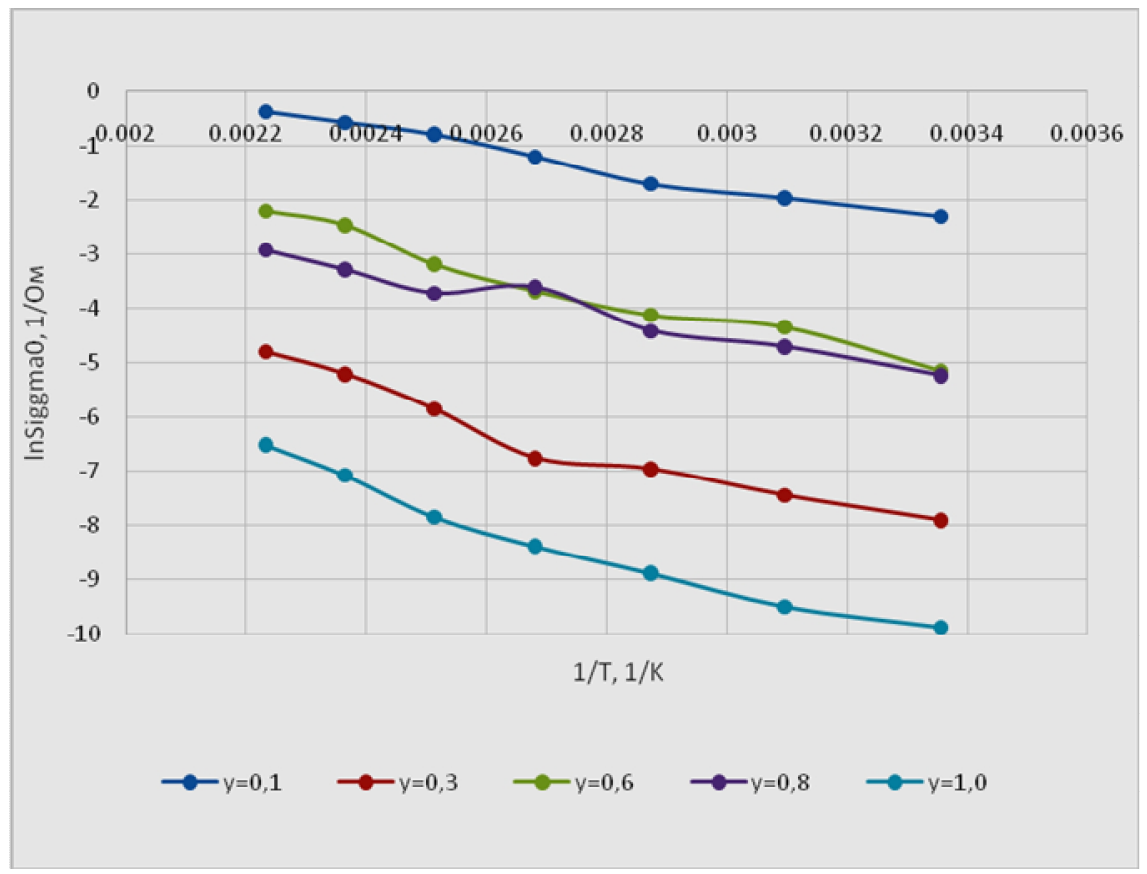

Fig. 5 b. Arrhenius curves (samples from Series 2). 


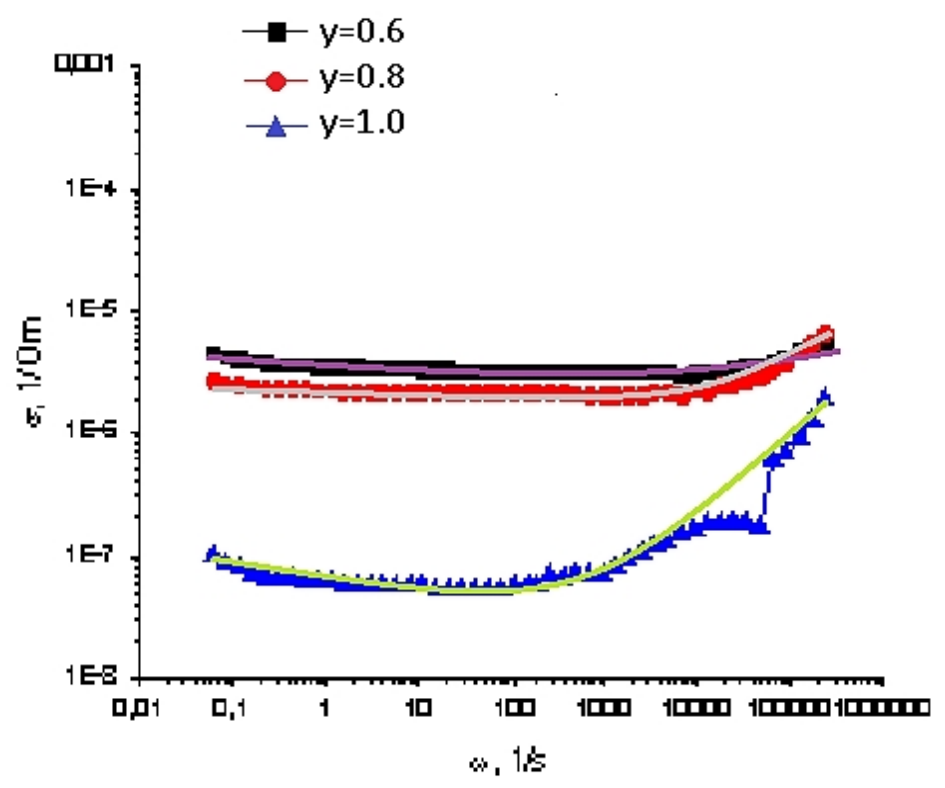

Fig. 6. Results of the approximation of the frequency dispersion of the specific conductivity by the superposition of the Jonscher equations (approximation curves are shown in solid lines) $(\mathrm{y}=0.8 ; \mathrm{T}=298 \mathrm{~K})$

Table 4

Simulation of the Jonsher's curve for the first series of samples

\begin{tabular}{|c|c|c|c|c|c|c|}
\hline $\begin{array}{c}\text { Aluminum } \\
\text { content y,\%; } \\
498 \mathrm{~K}\end{array}$ & $\sigma_{0 \mathrm{i}}, 1 / \mathrm{Om}$ & $\omega_{\mathrm{hi}}, \mathrm{s}^{-1}$ & $\mathrm{~s}_{\mathrm{i}}$ & $\sigma_{0 \mathrm{e}}, 1 / \mathrm{Om}$ & $\omega_{\mathrm{he}}, \mathrm{s}^{-1}$ & $\mathrm{~s}_{\mathrm{e}}$ \\
\hline 0.6 & $1.35 \cdot 10^{-6}$ & $4.6 \cdot 10^{-1}$ & 0.080 & $1.06 \cdot 10^{-6}$ & 62083 & 0.680 \\
\hline 0.8 & $7.70 \cdot 10^{-7}$ & $4.6 \cdot 10^{-2}$ & 0.027 & $8.96 \cdot 10^{-8}$ & 2885 & 0.897 \\
\hline 1.0 & $5.62 \cdot 10^{-5}$ & $1.16 \cdot 10^{-2}$ & 0.288 & $1.17 \cdot 10^{-5}$ & 1198 & 0.510 \\
\hline
\end{tabular}

energy of the $\mathrm{Li}^{+}$ions of a particular sample.

The problem of the separation of electronic and ionic conductivities is a complex experimental problem [17], which requires many limitations to be solved. On the other hand, the peculiarities of the frequency dispersion of conductivity for different types of current carriers can be a solution for isolating such contributions in the entire frequency range.

Both possible mechanisms are based in this case on the ability of $\mathrm{Li}^{+}$ions to move within the grain boundaries or at the grain boundaries, that is, to participate in the contribution to the overall conductivity.

Figure 6 shows the results of the approximation of the experimental dependence of $\sigma(\omega)$ on Al-substituted $\mathrm{Li}-\mathrm{Fe}-$ oxospinels calculated using equation (7).

The curve can be formed, as a superposition of two Jonsher's equations:

$$
\sigma(\omega)=\sigma_{\mathrm{e}}(\omega)+\sigma_{\mathrm{i}}(\omega)
$$

where $\sigma_{\mathrm{e}}(\omega)$ - electron, $\sigma_{\mathrm{i}}(\omega)$ - ion component of conductivity. Attributing to the respective charge carriers their characteristic hopping frequencies (resonant frequencies), the stationary conductivities of $\sigma_{0 e}(\omega)$ and $\sigma_{0 i}(\omega)$ and the constants $S_{e}$ and $S_{i}$, we obtain formula (5).

Table 4 shows the results of the approximation parameters.

Analyzing the data in Table 5, we can state that there's a contribution of electronic and ionic conductivity to the overall conductivity of the system. Ion conductivity accounts for only $10-30 \%$, and electronic $-70-90 \%$. This can be explained by the fact that as the degree of $\mathrm{Al}^{3+}$ substitution increases, separate phases are formed in the spinel structure, which conductivity is very small, since $\mathrm{Al}^{3+}$ completely displaces $\mathrm{Fe}^{2+}$. These phases can be considered as dielectric regions in the structure of spinel at the grain boundaries, on which charges accumulate as a result of electrostimulated migration of ions. Under the influence of an external electric field, these dielectric regions are polarized and, as a consequence, the charges that have accumulated at the grain boundaries pass through the grain and contribute to the conductivity of the system.

Table 5

Electronic and ionic conductivity components for the first series of samples

\begin{tabular}{|c|c|c|}
\hline $\begin{array}{c}\text { Aluminum content } \\
\mathrm{y}, \% \text {;emperature, } \\
\mathrm{K} .\end{array}$ & $\sigma_{0 \mathrm{e}}, \%$ & $\sigma_{0 \mathrm{i}}, \%$ \\
\hline $0.6 ; 498$ & 92 & 8 \\
\hline $0.8 ; 498$ & 94 & 6 \\
\hline $1.0 ; 498$ & 70 & 30 \\
\hline
\end{tabular}


In this paper an attempt to apply the Jonscher's phenomenological approach to determine the contributions of different current carriers to the conductivity of the system of Al-substituted Li-Fe oxospinels, as well as to determine the basic dispersion parameters of the electrical conductivity of a given disordered system was made. Obtained results proved the expediency of using this approach.

\section{Conclusions}

1. In this paper, an attempt to apply the Jonsher's phenomenological approach to determine the contributions of different current carriers to the conductivity of a system of Al-substituted $\mathrm{LiFe}$ oxospinels was made, as well as to determine the basic parameters of the electrical conductivity dispersion of this disordered system.

2. It is shown that, at low frequencies, an increase in the aluminum content leads to an increase in the conductivity activation energy. This is due to the displacement of divalent iron cations from the octa positions by aluminum and, as a consequence, to the reduction of the process intensity of charge transfer "percolation".

3. Conductivity is divided into electronic and ionic components and it is found that the contribution of ion transfer is low and its range is $10-30 \%$ depending on the aluminum content in the spinel structure.

Chervinko D.M. - Postgraduate student of the Materials Science and Emerging Technologies department;

Gasiuk I.M. - Doctor of Science, Professor of the Department of Materials Science and Emerging Technologies, dean of the Faculty of Physics and Technology;

Gasiuk M.I. - Postgraduate student of the Materials Science and Emerging Technologies department.

Lozinska L.Ya. - student.

[1] I.M. Gasyuk, Physics and chemistry of solid state 12(2), 275 (2011).

[2] V.O. Kotsyubinsky, V.V. Moklyak, A.B. Grubyak, P.I. Kolkovsky, A.H. Al-Saedi, Journal of Nano-and Electronic Physics 5(1), 01024 (2013).

[3] B.E. Levin, Yu.D. Tretyakov, L.M. Letiuk, Physics and chemistry of production, properties and application of ferrites (Metallurgy, Moscow, 1979).

[4] L.I. Rabkin, S.A. Soskin, B.S. Epstein, Ferrites. Structure, properties, production technology (Energy, Leningrad, 1968).

[5] B.Y. Deputat, Herald of the Vasyl Stefanyk Precarpathian National University. Chemistry of the solids (XXI), 59 (2011).

[6] B.K. Ostafiychuk, I.M. Gasyuk, L.S. Kaykan, V.V. Uhorchuk, P.P. Yakubovskiy, V.A. Tsap, Yu. S. Kaykan, Temperature Metallofizika i Noveishie Tekhnologii 36(1), 89 (2014) (doi: 10.15407/mfint.36.1.89-102).

[7] N.M. Olekhnovich, Yu. V. Radiush, A.V. Pushkariov, Physics of solids 54(11), 2103 (2012).

[8] O. Flunt, Theoretical Electrical Engineering (61), 60 (2010).

[9] N.M. Galiarova, Solid State Physics 31(11), 248 (1989).

[10] G.S. Grigoryan, A.M. Solodukh Solid State Physics 51(7), 1375 (2009).

[11] V.A. Kotsyubynsky, B.M. Ostafiychuk, V.M. Moklyak, A.B. Grubiak, International conference on Oxide Materials for electronic engeneering - fabrication, properties and applications (OMEE, Lviv, 2014), p. 79 (doi: 10.1109/OMEE.2014.6912348).

[12] I.I. Popov, R.R. Nigmatulin, A. A. Khazmin, I.V. Lounev, Journal of Applied Physics 112(101), 094107 (2012) (doi: 10.1063/1.4764343).

[13] A.A. Volkov, G.V. Kozlov, S.P. Lebedev, A.S. Rakitin, Physics of Solids 32(2), 329 (1990).

[14] M.N. Abdullah, A.N. Yosoff, Journal of Alloys and Compounds 233(1-2), 129 (1996) (doi: 10.1016/09258388(96)80044-2).

[15] S.S. Bashkirov, V.N. Doronin, A.B. Lieberman, V.V. Parfenov, Phys. Electronics (20), 74 (1980).

[16] N.M. Galiarova, Solid State Physics 31(11), 248 (1989).

[17] M.A. Arillo, M.L. Lopez, E. Perez-Cappe, C. Pico, M.L. Veiga, Solid State Ionics 107(3-4), 307 (1998) (doi: 10.1016 / S0167-2738 (97) 00537-7). 


\author{
I.М. Гасюк, Д.М. Червінко, М.І. Гасюк, Л.Я. Лозинська
}

\title{
Феноменологія температурно-частотної дисперсії електричних властивостей алюміній-заміщеної літій-залізної шпінелі
}

Прикарпатський національний університет імені Василя Стефаника, Івано-Франківськ, Украӥна, е-таіl: gasyukim@gmail.com, dmytro.chervinko@gmail.com

Досліджено електричну провідність зразків літієвмісного $\mathrm{Al}$-оксоферриту. За допомогою феноменологічної теорії Джоншера було підтверджено існування двох типів провідності (електронної та іонної) у вищезгаданих зразках. За допомогою методу Коула-Коула показано характер дисперсії електричної провідності зразків. Розраховано енергію активації для серії зразків. Було встановлено, що іонний внесок у загальну провідність системи значно нижчий, ніж відповідний електронний внесок.

Ключові слова: феноменологічна теорія Джоншера, метод Коула-Коула, дисперсія електричної провідності. 